\title{
Self-assessed Dental Status of the First Year Students of Health Related Faculties of a University in Turkey
}

\author{
Bahar Güçiz Doğan ${ }^{1}$ and Saadet Gökalp² \\ ${ }^{1}$ Hacettepe University, Faculty of Medicine, Ankara, Turkey \\ ${ }^{2}$ Hacettepe University, Faculty of Dentistry, Ankara, Turkey
}

Correspondence should be addressed to: Bahar Güçiz Doğan; bdogan@hacettepe.edu.tr

Received Date: 7 October 2013; Accepted Date: 11 November 2013; Published Date: 21 March 2014

Academic Editor: Eduardo Yugo Suzuki

Copyright (C) 2014 Bahar Güçiz Doğan and Saadet Gökalp. Distributed under Creative Commons CC-BY 3.0

\begin{abstract}
The objectives of this study are to determine the self-assessed oral health status and behavior of entrants educating in health related faculties of a university, Ankara, Turkey. There were currently four faculties namely Medicine, Pharmacy, Dentistry and Health Sciences in Hacettepe University with 964 first year students; 853 (88.5\%) of them were participated in this descriptive study. Data collected via a self-administered pre-tested questionnaire included items to evaluate the selfassessed oral health status and behaviour. All students were informed of the purpose of the study and how to fill the questionnaire. The data were analyzed using SPSS Version 15.0. Chi square test was performed to test the significance of the differences. $74.0 \%$ of the students were between 18 19 ages; two-thirds was female. In all, $40.8 \%$ of them were dissatisfied with the appearance of their teeth. Although half of the group stated that the dentist will propose treatment if they visit a dentist, most of them did not think that the health of their teeth and gingiva was good. The percentage of dental visit at least once among females (94.2\%) was more than males $(82.8 \%)$ $(p<0.001)$. Half of the students did not remember the age at first dental visit. $68.9 \%$ of the students had brushed their teeth at least twice a day. Improvements in preventive orientation of all health science students will also help them to play more effective roles in promoting the oral health of themselves as well as their communities.
\end{abstract}

Keywords: Oral health, University students, Behavior, Self-assessment, Turkey.

\section{Introduction}

Oral health is an essential component of general health and quality of life (Petersen, 2009). The relevance of oral health lies in the relationship between the effective oral health knowledge and the behavior (Dumitrescu et al., 2011). Generally, oral health knowledge is promoted by the development of effective education programs for oral health and

Cite this Article as: Bahar Güçiz Doğan and Saadet Gökalp (2014), "Self-assessed Dental Status of the First Year Students of Health Related Faculties of a University in Turkey," Journal of Research and Practice in Dentistry, Vol. 2014 (2014), Article ID 269657, DOI: 10.5171/2014.269657 
practice targeted at young people. They should be encouraged through health education to adopt regular oral hygiene habits such as twice daily brushing with fluoride toothpaste and pay regular visits to the dentist in their early life. Such behavior appears to be an essential part of many people's oral health. Therefore oral health behavior situations should be studied more extensively throughout the life.

In the literature, studies on the selfassessment, knowledge, attitude, and behavior of young adults toward oral health have been sparse (Levin, 2004) and most of them been carried out through the university students (Kassak et al., 2001; Sharda and Shetty, 2009; Neamatollahi et al., 2011; Kirtiloğlu and Yavuz, 2006; Coşkun Akar et al., 2009). Such studies have primarily been conducted among dental and medical students (Kawamura et al., 2005; Rong et al., 2006; Peker and Toraman Alkurt, 2009; Peker et al., 2010; Yildiz and Dogan, 2011).

Although researches related to oral health behaviours of young populations were infrequent in Turkey (Gökalp and Güçiz Doğan, 2009), some studies had been undertaken during the past 5 years through university students (Kirtiloğlu and Yavuz, 2006; Coşkun Akar et al., 2009) and most of the studies were conducted at all study levels of dental students (Peker and Toraman Alkurt, 2009; Peker et al., 2010; Yildiz and Dogan, 2011).

In Turkey, in general, no school-based oral health programs implemented to increase children's knowledge about oral diseases and help them to develop good oral health practices. Since the impact of good oral health practice in childhood could be seen at adolescence, investigating the self-assessed oral health status of university entrants might also give an idea about the overall status of adolescents.

The aim of this study was to evaluate the selfassessed dental health status and oral health behavior of university entrant students of health related faculties at Hacettepe University, Ankara, Turkey.

\section{Materials and Methods}

There are currently four faculties, namely Medical, Dental, Pharmaceutical and Health Science Faculties in Hacettepe University, with 964 first year students. Most students were from the Faculty of Medicine and Health Sciences due to Faculties of Pharmacy and Dentistry had lower number of students. Before the survey, Ethical Committee of Hacettepe University approval and verbal consent from the directors of the aforementioned faculties were obtained.

In this descriptive study, the data was gathered via a self administered questionnaire. The questionnaire was adapted from that developed for the study of "The Oral Health Profile of Turkey 2004" (Gökalp and Güçiz Doğan, 2009) and included 61 items designed to evaluate the oral health knowledge, behaviour and selfassessed oral health status of the students. Prior to the study, the questionnaire were pre-tested on 25 randomly selected university students from other universities. The students had no problem in understanding and answering the questions.

The data were collected at the very beginning of the academic year of 2008-2009. The questionnaires had been filled anonymously in the classrooms by the students before the lectures. Participation was on voluntary basis. All students were informed with a full explanation of the purpose of the study and how to fill the questionnaire. Each data collection session in the classrooms was supervised by one of the investigators. No attempt were made to follow up with students who were absent on the day of the survey but the number of the absent and refusal were recorded.

The first part of the questionnaire was related to the socio-demographic variables: age in years, sex, residence lived until the age of 12 , health security status, and level of 
parental education and employment. In the second part of the questionnaire, the following principal variables were covered: behavior related to tooth brushing such as time of starting tooth brushing, interval of replacing toothbrush, frequency of tooth brushing; consumption of sweet food/drink between meals and status of visiting to a dentist, and self assessment of the status of their teeth. Students' knowledge regarding tooth brushing such as frequency, duration, interval of replacing toothbrush and properties for tooth paste was also recorded.

The data were analysed using the SPSS Version 15.0 (SPSS, Inc., Chicago, IL, USA). Chi square test was performed to test the significance of the differences in bivariate analysis. A p value of $<0.05$ was considered statistically significant.

\section{Results}

A total of 853 students (35.4\% males, $64.5 \%$ females) participated in the survey between the ages of 17 to 24 (mean age was $18.9 \pm 1.2$ ). Fathers had higher educational level than mothers (47.9 \%, 27.8\%), respectively. Ninety point two percent of students had health security but $44.7 \%$ of them thought that it does not cover the dental problems even it covers.

Female students ate snacks between main meals $(90.2 \%)$ significantly more than males $(73.9 \%) \quad(p<0.001)$. The most consumed goods for both sexes were sweet foods like biscuits, cake, etc. (73.1\%).

Almost two-third of the students was never smoker, and $15.9 \%$ of males, and $8.2 \%$ of females were current smokers $(p<0.001)$.

It was found that $82.8 \%$ of males and $94.2 \%$ of females had ever visited a dentist ( $\mathrm{p}<0.001)$; only $8.9 \%$ of females and $6.8 \%$ of males were visiting the dentist regularly $(p=0.002) \quad$ (Table 1). Very few of the participants (5.0\% of females; $7.2 \%$ of males) stated that they have visited a dentist when they were at the age of preschool, and $47.9 \%$ of males and $32.4 \%$ of females had their first visit between the ages 6 to 14. More than half of the total had not remembered the age at first visit. Among respondents who claimed having had a recent dental visit, only $16.9 \%$ reported that the reason was control.

Table 1. Some Characteristics of Participants Related to Dental Visit by Sex (Ankara-Turkey, 2008)

\begin{tabular}{|l|r|r|r|r|r|}
\hline & & & \multicolumn{2}{|c|}{ Total } & \\
\cline { 4 - 6 } Characteristics & Male & Female & $\mathrm{n}$ & $\%$ & $\mathrm{p}$ \\
\hline Ever visiting dentist & $(\mathrm{n}=303)$ & $(\mathrm{n}=550)$ & $(\mathrm{n}=853)$ & & \\
Yes & 82.8 & 94.2 & 769 & 90.1 & $<0.001$ \\
No & 13.5 & 4.9 & 68 & 8.0 & \\
Don't remember & 3.6 & 0.9 & 16 & 1.9 & \\
\hline Frequency of visiting & $(\mathrm{n}=251)$ & $(\mathrm{n}=518)$ & $(\mathrm{n}=769)$ & & \\
Regularly & 6.8 & 8.9 & 63 & 8.2 & 0.002 \\
Occasionally & 16.3 & 26.4 & 178 & 23.1 & \\
When having a complaint & 76.9 & 64.7 & 528 & 68.7 & \\
& & & & & \\
\hline First five reasons for last visit* & $(\mathrm{n}=251)$ & $(\mathrm{n}=518)$ & $(\mathrm{n}=769)$ & & \\
Extraction & 21.1 & 16.5 & 155 & 20.2 & \\
Cleaning & 14.5 & 17.1 & 138 & 17.9 & $*$ \\
Check-up & 14.9 & 15.5 & 130 & 16.9 & \\
Decay/filling & 8.9 & 17.1 & 121 & 15.7 & \\
Pain & 8.6 & 12.5 & 95 & 12.4 & \\
\hline
\end{tabular}

* More than single response; percentages were calculated on the basis of ever dental visitors. No significance test was performed. 
More than one-fifth of the participants $(22.7 \%)$ stated that they felt no fear and $62.5 \%$ of the group felt fear in various levels from "excessive" to "some fear" at the first dental visit. Even there was no statistically significant difference, females report higher levels $(25.1 \%)$ of excessive dental fear than males $(16.4 \%)(p=0.076)$.

Table 2. Percent Distribution of Feelings of Participants at the First Dental Visit (Ankara-Turkey, 2008)

\begin{tabular}{|l|r|r|r|r|}
\hline Feelings & & & \multicolumn{2}{|c|}{ Total } \\
\cline { 4 - 5 } & Male & Female & $\mathrm{n}$ & $\%$ \\
\hline Excessive fear & 16.4 & 25.1 & 171 & 22.3 \\
Moderate fear & 28.8 & 26.3 & 208 & 27.1 \\
Some fear & 13.6 & 13.1 & 102 & 13.3 \\
No fear & 26.4 & 20.8 & 174 & 22.7 \\
Don't remember & 14.8 & 14.7 & 113 & 14.7 \\
\hline Total & 251 & 518 & $768^{*}$ & 100.0 \\
\hline
\end{tabular}

* 68 participants never visited dentist, 16 participants did not remember whether they visit or not and one participant had not answer this question.

Among the never dental visitors $(n=68 ; 41$ male, 27 female), $83.8 \%$ claimed that there was no complaint to visit a dentist (Table 2). "Fear of drilling" and "fear of injection" were the reasons stated by female non-visitors more than males.

Hundred percent of females and $97.0 \%$ of males had tooth brush $(\mathrm{p}<0.001)$. Among the students who had tooth brush, $68.9 \%$ of them were brushing their teeth at least twice a day; $99.2 \%$ of them use fluoride toothpaste; females had significantly more proper behavior than males. Almost three-fourth of the students claimed that the amount of toothpaste they used was equal to pea size (71.9\%). Most of them (79.4\%) reported that they brush their teeth before going to sleep and $39.6 \%$ of them claimed brushing time for 2 minutes (Table 3). The prevalence of replacement time (<=6 months) of the tooth brush was $75.7 \%$. 
Table 3. Percent Distribution of Some Characteristics of Participants Related to Tooth Brushing by Sex (Ankara-Turkey, 2008)

\begin{tabular}{|l|r|r|r|r|}
\hline Characteristics* & Male & Female & Total & $\mathrm{p}$ \\
\hline Has tooth brush & $\mathrm{n}=330)$ & $(\mathrm{n}=550)$ & $(\mathrm{n}=853)$ & \\
Yes & 97.0 & 100.0 & 98.8 & $<0.001^{* *}$ \\
No & 2.6 & - & 1.1 & \\
\hline Frequency of brushing (daily) & $\mathrm{n}=294)$ & $(\mathrm{n}=550)$ & $(\mathrm{n}=844)$ & \\
Less than 1 & 9.9 & 1.3 & 4.3 & $<0.001$ \\
Once & 36.1 & 19.8 & 25.5 & \\
Twice & 43.9 & 65.8 & 58.2 & \\
Three or more & 6.8 & 12.7 & 10.7 & \\
\hline Time of tooth brushing** & $\mathrm{n}=294)$ & $(\mathrm{n}=550)$ & $(\mathrm{n}=844)$ & \\
After awakening & 40.1 & 40.2 & 40.2 & \\
After breakfast & 38.8 & 60.0 & 52.6 & $* * *$ \\
After lunch & 6.5 & 16.4 & 12.9 & \\
After dinner & 16.7 & 24.0 & 21.4 & \\
Before going to bed & 71.4 & 83.6 & 79.4 & \\
Other**** & 3.1 & 2.7 & 1.6 & \\
\hline Brushing period & $(\mathrm{n}=294)$ & $(\mathrm{n}=550)$ & $(\mathrm{n}=844)$ & \\
No idea & 10.2 & 10.5 & 10.4 & \\
Less than 1 min. & 6.5 & 4.5 & 5.2 & \multirow{2}{*}{0.002} \\
1 minute & 21.4 & 26.7 & 24.9 & \\
2 minutes & 41.2 & 38.7 & 39.6 & \\
More than 2 minutes & 19.7 & 19.1 & 19.3 & \\
\hline Amount of tooth paste used & $(\mathrm{n}=288)$ & $(\mathrm{n}=549)$ & $(\mathrm{n}=837)$ & \\
every time & 11.5 & 15.7 & 14.2 & $<0.001$ \\
Lentil size & 70.1 & 72.9 & 71.9 & \\
Pea size & 18.4 & 11.5 & 13.9 & \\
Tooth brush size & & & \\
\hline
\end{tabular}

* Various amount of non response for each question.

** Fisher's Exact Chi Square Test

*** More than single response; percentages were calculated on tooth brush owners. No significance test was performed.

**** Before going out and after coming home; sometimes after eating snack; after eating sweet foods; after meals; when having an important interview.

Eighty-four point two percent of the students thought that the status of their teeth and $88.9 \%$ their gums were good or moderate. Almost half of the students was not satisfied the appearance of their teeth, and more than half of them thought that they did not need dental treatment (Table 4). 
Table 4. Percent Distribution of Opinions of the Participants about Their Dental Health Status by Sex (Ankara-Turkey, 2008)

\begin{tabular}{|c|c|c|c|c|c|}
\hline \multirow[b]{2}{*}{ Opinions* } & \multirow{2}{*}{$\begin{array}{r}\text { Male } \\
(n=303)\end{array}$} & \multirow{2}{*}{$\begin{array}{r}\text { Female } \\
(\mathrm{n}=550)\end{array}$} & \multicolumn{2}{|c|}{ Total $(n=853)$} & \multirow[b]{2}{*}{$\mathrm{p}$} \\
\hline & & & $\mathrm{n}$ & $\%$ & \\
\hline Status of teeth & & & & & \\
\hline Very good & 5.3 & 3.6 & 36 & 4.2 & 0.540 \\
\hline Good & 32.3 & 36.7 & 300 & 35.2 & \\
\hline Moderate & 48.8 & 49.1 & 418 & 49.0 & \\
\hline Bad & 10.9 & 8.9 & 82 & 9.6 & \\
\hline Very bad & 1.7 & 1.6 & 14 & 1.6 & \\
\hline Gingival status & & & & & \\
\hline Very good & 8.6 & 6.5 & 62 & 7.3 & 0.553 \\
\hline Good & 39.6 & 44.7 & 366 & 49.2 & \\
\hline Moderate & 40.3 & 39.5 & 339 & 39.7 & \\
\hline Bad & 9.6 & 8.0 & 73 & 8.6 & \\
\hline Very bad & 1.0 & 1.3 & 10 & 1.2 & \\
\hline Satisfaction from the & & & & & \\
\hline $\begin{array}{l}\text { appearance of their teeth } \\
\text { Satisfied }\end{array}$ & 59.4 & 58.5 & 502 & 58.9 & 0.680 \\
\hline Not satisfied & 39.6 & 41.5 & 348 & 40.8 & \\
\hline Self perceived treatment need & & & & & \\
\hline Yes & 43.9 & 50.7 & 412 & 48.3 & 0.068 \\
\hline No & 55.4 & 49.3 & 439 & 51.5 & \\
\hline
\end{tabular}

* Various amount of non response for each question.

When it was asked as "what will be the suggestions if you have visited a dentist", less than $1 \%$ of the group answered as "nothing". Both male and female students thought that the dentist will suggest them "to brush their teeth more properly" (41.9\% males, $28.7 \%$ females), "they should have had some filling" (25.4\% males, $32.7 \%$ females) and "they should have had some orthodontic intervention" (20.5\% males, $24.7 \%$ females).

\section{Discussion}

The use of questionnaires has become a more common method for performing oral health surveys. This study had evaluated the selfassessed oral health status and behavior on the basis of a pre-tested self-administered questionnaire. The questionnaire gathers information about the self assessed dental health as well as visit to the dentist, reasons for never visiting the dentist and tooth brushing behaviour.

Having snacking between the meals has been found to be higher among females (90.2\%) than the males $(73.9 \%)(\mathrm{p}<0.001)$. This study has also found a significantly higher percentage of females than males who consume sugary foods and drinks such as biscuits, cakes, cola and soda $(\mathrm{p}<0.001)$. Most of US students reported eating sugary foods 1 to 3 times weekly or once daily but there were no sex differences (Luebke and Driskell, 2010). While it may not be able to force students to change his/her diet, simple modifications to diet and lifestyle could be encouraged.

More than half of the students reported that they never smoked but the percentage of male smoking was significantly higher than females. This finding agrees with the results of lots of studies (Erguder et al., 2008; Erbaydar et al., 2002; Akpınar et al., 2006; AlOmari and Hamasha, 2005). In this study, even the percentages related to smokers were relatively low, they could be considered still high for this age group. 
The young adult participants in the present study were drawn from a university student population characterized by urban and semiurban origins. Consequently, it is rational to suppose that the studied sample showed relatively better self-preventive care attitude as visiting the dentist regularly than that of the 15 years of age Turkish population reflecting on the frequency of self-reported attendance of regular dental visit as $11.3 \%$ (Gökalp and Güçiz Doğan, 2009). The prevalence found in the present study (8.2\%) which is significantly higher among female students was far more less than in another Turkish university students' study (30.3\%) (Kırtıloğlu and Yavuz, 2006). In contrast to current study, there was no significant difference in the regularity of visits to the dentist between females and males done in the abovementioned Turkish university study. In agreement with previous Turkish national study (Gökalp and Güçiz Doğan, 2009), the results demonstrated that utilization of dental services among the students was highly symptom oriented (68.7\%).

More than one-third of females and more than half of males had visited a dentist before the age of 15 . Females report higher but not significant levels of fear than males at their first dental visit $(p=0.076)$. When it is considered that the fear in the childhood sometimes resulted with improper behaviour, it is important to learn the fear experience at the first dental visit. An Iranian study evaluated parental view about the origins of the dental fear in children and revealed that previous dental experience was a major factor in the development of childhood dental fear (Jafarzadeh et al., 2011). Preventive health education and intervention programs may prevent and reduce dental fear and promote oral health.

Most of behavioural patterns were established in early childhood. Twice daily brushing with fluoride toothpaste plays an essential role in the prevention and control of dental caries and periodontal diseases. Most of the participants included in this study stated that they use toothbrush and toothpaste. In an Israel study in which study sample consisted of eighteen to twenty-one years old army personnel declared that twothird brushed their teeth once a day (Samorodnitzky and Levin, 2005). The similar results $(58.2 \%$ twice a day) were obtained in this study which indicated that tooth brushing practices of the students were still far behind the European and North American reports (Maes et al., 2006) e.g. 92.1\% of Italian university students brushed their teeth at least twice a day (Rimondini et al., 2001).

The present study agreed with another Turkish university students' study (Kırtıloğlu and Yavuz, 2006) in finding significant differences in the prevalence of tooth brushing by sex. For this age group, most of the studies showed same result that tooth brushing habit was more prominent in females than in males (Tada and Hanada, 2004; Al-Omari and Hamasha, 2005).

According to the results, the students were brushing their teeth with tooth paste (99.2\%). More than $60 \%$ US students reported using fluoride-containing toothpaste which was less than Turkish students (Luebke and Driskell, 2010). This result may be due to that in Turkey, companies were selling mostly fluoridated toothpaste. On the contrary of an Iranian study, the sex difference about the use of fluoridated toothpaste was not significant (Khami et al., 2007).

Lentil size amount of toothpaste is recommended for tooth-brushing. In this study, it was found that $14.2 \%$ of the students were using toothpaste lentil size while $71.6 \%$ pea size. Females had more proper behaviour than males $(p<0.001)$. Although the manufacturers use the amount of the length of toothbrush in their advertisements in Turkey, it may due to that most of the students knew the larger amount of toothpaste does not improve the effect of the mechanical cleaning or the preventive effect of fluoride. 
In the present study, when the opinions of the students regarding the health status of their teeth and gums were asked, a similar percentage from good to moderate was obtained. This finding was also found for health status of teeth in a study conducted among young Israeli army personnel (Samorodnitzky and Levin, 2005). One-third of the students tended to be satisfied with their own dental health and $58.9 \%$ of the participants were satisfied with the appearance of their teeth as reported in a Swedish study (59\%) (Stenberg et al., 2000). The result of present study may explain why most of them visited a dentist only when they really need treatment with their teeth or gums $(68.7 \%)$, and not for regular visits (8.2\%).

In a study among university students at the Kuwait University Health Science Centre, almost $31.7 \%$ had visited a dentist for a check-up (Al-Hussaini et al., 2003), with higher percentage than in this study. These results may be due to differences between the study populations that Kuwaitis were studying in various classes. Another study reported that $95 \%$ of $14-, 16-$ and 18-yearold Finns visited dentist at least every second year. (Honkala et al., 1997). In contrast to Finland, Turkish young people were not enrolled to free dental check-ups and dental care by the Public Dental Health Services and the Student Health Service did not provide regular dental check-ups for the students during their study years. If the regular checkups will be free of charge, they were more likely to perform regular self-care practices.

The information presented in this study could serve as a tool for public and preventive dentistry. In particularly, there is a need such studies which examine the general student population before entering the universities in Turkey. As being the potential health care personnel, their attitude not only affects their own oral health behavior but also potentially influence the health behavior of their patients and community.

\section{Conclusion}

The oral health practices of the entrant students were lower than expected. Although more than four-fifth of students thought that the status of their teeth and gums were good or moderate and more than half of them thought that they did not need dental treatment, almost all of them thought that if they have visited a dentist he/she will suggest some treatments or more proper tooth-brushing. These results make think that students could not correlate oral hygiene practices and oral health status. Community authorities must make efforts to develop school-based oral health programs before students enter the university. It is, also in Turkish medical and health sciences faculties, the responsibility of all health educators to increase their students' awareness and knowledge of preventive measures and to promote positive attitudes towards dental care by changing their curriculum into a more oral health care oriented one. Improvements in preventive orientation of all health science students will also help them to play more effective roles in promoting the oral health of themselves as well as their communities.

\section{Acknowledgement}

The authors are grateful to Hacettepe University for funding (Project No. 0801201 001). We offer our special thanks to the students who volunteered to participate in the effort.

\section{References}

Akpınar, E., Yoldaşcan, E. \& Saatçi, E. (2006). "The Smoking Prevalence and the Determinants of Smoking Behavior among Students in Çukurova University, Southern Turkey," (2006) West Indian Medical Journal, 55(6):414-9.

Al-Hussaini, R., Al-Kandari, M., Hamadi, T., AlMutawa, A., Honkala, S. \& Memon, A. (2003). "Dental Health Knowledge, Attitudes and Behavior among Students at the Kuwait 
University Health Sciences Centre," Medical Princ[ples and Practice, 12(4):260-5.

Al-Omari, Q. D. \& Hamasha, A. A. (2005). "Gender-Specific Oral Health Attitudes and Behavior among Dental Students in Jordan," Journal of Contemporary Dental Practice, 6: 15.

Coşkun Akar, G., Özmutaf, N. M. \& Özgür, Z. (2009). "An Assessment of Self-Reported Oral Health Behavior Non-Dental School Students in Turkey," Acta Stomatologica Croatica, 43(1):13-23.

Dumitrescu, A. L., Wagle, M., Dogaru, B. C. \& Manolescu, B. (2011). "Modeling the Theory of Planned Behavior for Intention to Improve Oral Health Behaviors: The Impact of Attitudes, Knowledge, and Current Behavior," (2011) Journal of Oral Science, 53(3):369-77.

Erbaydar, T., Dağll, E., Hayran, O., Ayla, F., Lawrence, S., Collinshaw, N. E. \& Callard, C. (2002). "Smoking Patterns of Youth in Turkey," (2002) Project No. 001726-022, Final Report, Istanbul. http://www.idrc.ca/uploads/user-

S/12107777871Final_report-Jan14,2003.pdf.

Erguder, T., Cakir, B., Aslan, D., Warren, C. W., Jones, N. R. \& Asma, S. (2008). "Evaluation of the Use of Global Youth Tobacco Survey (GYTS) Data for Developing Evidence-Based Tobacco Control Policies in Turkey," (2008) BMC Public Health; Suppl 1:S4.

Freed, J. R. \& Goldstein, M. S. (1976). "Dental Health What is Being Taught to College Students," Journal of the American Dental Association, 92; 940-5.

Gökalp, S. \& Güçiz Doğan, B. (2009). 'Türkiye Ağız-Diş Sağlığı Profili 2004,' (2009) 2. Basım. Hacettepe Üniversitesi Yayınları. Hacettepe Üniversitesi Hastaneleri Basımevi. ISBN: 978-975-491-270-8.

Honkala, E., Kuusela, S., Rimpelä, A., Rimplelä, M. \& Jokela, J. (1997). "Dental Services Utilization between 1977 and 1995 by
Finnish Adolescents of Different Socioeconomic Levels," Community Dentistry and Oral Epidemiology, 25:383-390.

Kassak, K. M., Dagher, R. \& Doughan, B. (2001). "Oral Hygiene and Lifestyle Correlates among New Undergraduate University Students in Lebanon," Journal of American College Health, 50(1):15-20.

Kawamura, M., Wright, F. A., Declerck, D., Freire, M. C, Hu, D. Y., Honkala, E, Lévy, G., Kalwitzki, M., Polychronopoulou, A., Yip, H. K., Kinirons, M. J., Eli, I., Petti, S., Komabayashi, T., Kim, K. J., Razak, A. A., Srisilapanan, P. \& Kwan, S. Y. (2005). "An Exploratory Study on Cultural Variations in Oral Health Attitudes, Behaviour and Values of Freshman (First-Year) Dental Students," International Dental Journal, 55(4):205-11.

Khami, M. R., Virtanem, J. I., Jafarian, M. \& Murtomaa, H. (2007). "Oral Health Behavior and it's Determinants amongst Iranian Dental Students," European Journal of Dental Education, 11: 42-47.

Kirtiloğlu, T. \& Yavuz, U. S. (2006). “An Assessment of Oral Self-Care in the Student Population of a Turkish University," Public Health, 120(10):953-7.

Komabayashi, T., Kawamura, M., Kim, K. J., Wright, F. A., Declerck, D., Goiâs M. do, C., Hu, D. Y., Honkala, E., Lévy, G., Kalwitzki, M., Polychronopoulou, A., Yip, K. H., Eli, I., Kinirons, M. J., Petti, S., Srisilapanan, P., Kwan, S. Y. \& Centore, L. S. (2006). "The Hierarchical Cluster Analysis of Oral Health Attitudes and Behaviour Using the Hiroshima University-Dental Behavioural Inventory (HU-DBI) among Final Year Dental Students," International Dental Journal, 56(5):310-6.

Levin, L. \& Shenkman, A. (2004). "The Relationship between Dental Caries Status and Oral Health Attitudes and Behavior in Young Israeli Adults," Journal of Dental Education, 68(11):1185-91. 
Luebke, T. E. \& Driskell, J. A. (2010). “A Group of Midwestern University Students Needs to Improve Their Oral Hygiene and Sugar/Pop Consumption Habits," Nutrition Research, 30(1):27-31.

Maes, L., Vereecken, C., Vanobbergen, J. \& Honkala, S. (2006). "Tooth Brushing and Social Characteristics of Families in 32 Countries," International Dental Journal, 56(3):159-67.

Neamatollahi, H., Ebrahimi, M., Talebi, M., Ardabili, M. H. \& Kondori, K. (2011). "Major Differences in Oral Health Knowledge and Behavior in a Group of Iranian Pre-University Students: A Cross-Sectional Study," Journal of Oral Science, 53(2):177-84.

Özalp, N., Dağ, C. \& Ökte, Z. (2012). "Oral Health Knowledge among Dental Students," Clinical Dentistry and Research, 36(1): 18-24.

Park, D. Y., Ma, D. S. \& Horowitz, A. M. (2004). "Oral Health Education Courses for University Students: Why Not?," Journal of Public Health Dentistry: 64(1), 3-4.

Peker, I. \& Alkurt, M. T. (2009). "Oral Health Attitudes and Behavior among a Group of Turkish Dental Students," European Journal of Dentistry, 3: 24-31.

Peker, K., Uysal, Ö. \& Bermek, G. (2010). "Dental Training and Changes in Oral Health Attitudes and Behaviors in Istanbul Dental Students," Journal of Dental Education, 74:1017-1023.

Petersen, P. E. (2009). "Global Policy for Improvement of Oral Health in the 21st Century - Implications to Oral Health Research of World Health Assembly 2007, World Health Organization," Community Dentistry and Oral Epidemiology, 37: 1-8.
Rong, W. S., Wang, W. J. \& Yip, H. K. (2006). "Attitudes of Dental and Medical Students in Their First and Final Years of Undergraduate Study to Oral Health Behaviour," European Journal of Dental Education, 10(3):178-84.

Samorodnitzky, G. R. \& Levin, L. (2005). "SelfAssessed Dental Status, Oral Behavior, DMF, and Dental Anxiety," Journal of Dental Education, 69(12):1385-9.

Sharda, A. J. \& Shetty, S. (2009). "Relationship of Periodontal Status and Dental Caries Status with Oral Health Knowledge, Attitude and Behavior among Professional Students in India," International Journal of Oral Science, 1(4):196-206.

Stenberg, P., Hakansson, J. \& Akerman, S. (2000). "Attitudes to Dental Health and Care among 20 to 25-Year-Old Swedes: Results from a Questionnaire," Acta Odontologica Scandinavica, 58:102-6.

Tada, A. \& Hanada, N. (2004). "Sexual Differences in Oral Health Behavior and Factors Associated with Oral Health Behavior in Japanese Young Adults," Public Health, 118, 104-109.

Yildiz, S. \& Dogan, B. (2011). 'Self Reported Dental Health Attitudes and Behavior of Dental Students in Turkey,' European Journal of Dentistry, 5(3):253-9.

Rimondini, L., Zolfanelli, B., Bernardi, F. \& Bez, C. (2001). "Self-Preventive Oral Behavior in an Italian University Student Population," Journal of Clinical Periodontology, 28(3):20711 